\title{
A Society Relearning How to Talk with Itself
}

\author{
JEFF JARVIS, Craig Newmark Graduate School of Journalism at CUNY
}

\begin{abstract}
In the hopes of technologists and optimists, the internet promised to connect humankind, to bring freedom of expression and creativity to all, to make institutions more open, equitable, accountable, and ultimately democratic. But malign actors exploited the net's openness, and institutions found themselves threatened in a borderless world they could not master. And so government and media are trying to regulate and restrain a phenomenon that is still too new to fully understand, without sufficient research and evidence of the harm they think they are answering. The internet is not, as it is commonly understood, a medium filled with content to be edited (or censored). It is a mechanism for connection that is enabling a post-Gutenberg, post-textual, post-mass society to relearn how to hold a conversation with itself. Government, media, and other institutions must create flexible, responsive, open frameworks not to eliminate allegedly harmful speech but instead to enable, improve, and protect the public conversation.
\end{abstract}

CCS Concepts: • General and reference $\rightarrow$ General literature; • Information systems $\rightarrow$ Blogs; Social recommendation; Web applications; Social networks;

Additional Key Words and Phrases: Society relearning, freedom of expression and creativity to all

ACM Reference format:

Jeff Jarvis. 2020. A Society Relearning How to Talk with Itself. Digit. Gov.: Res. Pract. 1, 1, Article 4 (January 2020), 10 pages. https://doi.org/10.1145/3352461

Twenty-five years ago, in the beginning of the widespread web, I hoped the internet could enable government and my field, media, to be more responsive, inclusive, equitable, collaborative, transparent, and accountable-in short, more democratic. That still could happen; in scattered cases, it has. But what I did not predict was how much these institutions would come into competition and conflict with the net.

I should have seen it coming. Gutenberg-like, the net is proving to disrupt and thus threaten every entrenched institution and industry in society by bypassing mediators and opening up the public conversation to new voices long unheard. The net's primary proprietors-so far, the platforms-have become so big, so global, and so powerful as to seem to be sovereign. The late John Perry Barlow warned of this clash in his seminal if slightly over-thetop 1996 Declaration of the Independence of Cyberspace, which he addressed directly to "Governments of the Industrial World, you weary giants of flesh and steel." Speaking for the people-not the platforms-he instructed government:

You have no sovereignty where we gather. We have no elected government, nor are we likely to have one, so I address you with no greater authority than that with which liberty itself always speaks. I declare the global social space we are building to be naturally independent of the tyrannies you seek

Authors' addresses: J. Jarvis, Craig Newmark Graduate School of Journalism at CUNY, 219 W. 40th St., New York, NY 10019; email: jeff@buzzmachine.com.

Permission to make digital or hard copies of part or all of this work for personal or classroom use is granted without fee provided that copies are not made or distributed for profit or commercial advantage and that copies bear this notice and the full citation on the first page. Copyrights for third-party components of this work must be honored. For all other uses, contact the owner/author(s).

(c) 2020 Copyright held by the owner/author(s).

2639-0175/2020/01-ART4

https://doi.org/10.1145/3352461

Digital Government: Research and Practice, Vol. 1, No. 1, Article 4. Publication date: January 2020. 
to impose on us. You have no moral right to rule us nor do you possess any methods of enforcement we have true reason to fear. ${ }^{1}$

In a brief, shining, optimistic moment, the net did provide the opportunity for citizens to exercise their human rights of freedom of expression and assembly-that is, of conversation-helping movements coalesce as the Indignados of Spain, Occupy Wall Street, the Arab Spring, and more. A growing list of governments reacted with fear, cracking down on the net and its rights in Iran, Russia, Egypt, the Philippines, Myanmar, Saudi Arabia, Hungary, Turkey, and elsewhere.

In Europe, governments are flexing their legislative and regulatory methods of enforcement against primarily the American platforms, trying to reduce their power but often, under the law of unintended consequences, accomplishing the opposite. The right to be forgotten decision in EU courts gave Google the power to decide what may and may not be remembered in search. Germany's NetzDG hate-speech law gave Facebook the power to decide what is manifestly illegal, hateful, and even merely insulting, with the platform playing police, prosecutor, judge, jury, and jailer. Articles 15 and 17 of the new EU Copyright Directive give internet companies the mandate to stop users from quoting unlicensed content longer than an undefined snippet, requiring monitoring systems that only the largest companies will be able to afford; the rest may be forced to throttle the tools that enable the public conversation. A recent UK Commons report wishes to hold not only internet companies but also engineers inside them liable for large fines if they fail to take down content that is reputedly harmful to society. ${ }^{2}$ These private companies are being assigned by public institutions to Bowdlerize the public conversation for the protection of the public. Europeans may argue that their regulation is a necessity to assure freedom on the net. I am dubious, for much of their legislation arose out of lobbying by publishers, who cashed in their political capital in an effort to restrain the commerce of their new competitors. At least sometimes, restraints on the net rise out of a protectionist reflex on behalf of media, government, and other institutions threatened by the new.

A 2018 paper by Kieron O’Hara and Wendy Hall warns that governance-or attempted governance-of the internet is balkanizing it into multiple realms: Silicon Valley's open internet (which holds to a doctrine of net neutrality and edge-to-edge freedom); an American commercial internet (where online resources are understood as "private property, whose owners can monetize them, exclude others from using them and seek market rates for their use"); Europe's regulated or "bourgeois internet" ("where trolling and bad behavior are minimized and privacy protected, possibly at the cost of innovation"), the authoritarian internet of China and too many other governments (which, unlike mere platforms and advertisers, use surveillance on the net as a tool of social control); and the growing misinformation internet of Russia and North Korea (where openness is a vulnerability to be exploited). ${ }^{3}$

At the e-G8 summit in France convened in 2011 by then-president Nicolas Sarkozy, I asked him to take a Hippocratic oath for the internet: to first do no harm. He mocked the question, asking whether it is harmful to protect intellectual property, security, and children. I had used the metaphor of an American government official who called the net the eighth continent, and I think Sarkozy rather liked the idea of planting a flag in that new land. "If we say that you wanted the eighth continent to be the continent of freedom and openness, we say that mustn't give rise to new monopolies. Is that harmful?" he said. But toward the end of his reply, he shifted slightly and added, addressing a tent full of technologists: "We mustn't enact any measures that would complicate the development of this system. I agree with you, yes indeed... The idea of regulating once and for all is ill-suited to your economy." ${ }^{4}$ I wonder whether he would say that still.

\footnotetext{
$\overline{{ }^{1} \text { https://www.eff.org/cyberspace-independence. }}$

${ }^{2}$ https://publications.parliament.uk/pa/cm201719/cmselect/cmcumeds/1791/179102.htm.

${ }^{3}$ Kieron O'Hara and Wendy Hall. 2018. Four internets: The geopolitics of internet governance. Center for International Governance Innovation (December 2018). Retrieved November 28, 2019 from https://www.cigionline.org/sites/default/files/documents/Paper\%20no.206web.pdf.

${ }^{4}$ https://youtu.be/N_bara_VrIs?t=2895.
}

Digital Government: Research and Practice, Vol. 1, No. 1, Article 4. Publication date: January 2020. 
Therein lies the conflict being argued out in every capital, every technology boardroom, and countless classrooms: What is the proper assurance of online freedom? What is the reasonable role of regulation? Does it stifle freedom of expression or protect it? We have seen this debate before, of course. After the introduction of movable type by Johannes Gutenberg in the mid-15th century, princes, kings, bishops, and popes feared the loss of control that printing threatened-and not without reason, given various peasants' wars, a Thirty Years' War, and the Reformation-and so rulers tried to assert control via licensing and censorship. Printing played a role (not deterministic) in the Scientific Revolution, in the redefinition of education (and thus of childhood), and-by the standardization and separation of languages-in the creation of our modern notions of publics, the nation, and nationality.

Now here comes the net, crossing borders, enabling war with coding and misinformation instead of gunpowder as its weapons, threatening to rival the power of the state to issue currency and influence economies, challenging the very idea of the nation. Perhaps that challenge is a key reason we are seeing the rise of nationalism around the world. In a recent panel discussion at the City University of New York Graduate Center, author and columnist Anne Applebaum noted the paradoxical rise of a "nationalist internationale" (and she added that when they meet, nationalists of different nations find they don't much like each other). ${ }^{5}$

It is early days still, very early. After the popularization of movable type, it took a half century before the book left its scribal roots and took the form we now know. It took a century before its impact on society was greatly realized. And it took a century and a half-until 1605-before that self-evident enterprise, the newspaper, was born. By that timetable, we are today-a quarter century from the introduction of the commercial web in 1994-only at 1475 in Gutenberg years. Martin Luther was not born until 1483; his Reformation did not begin until 1517. We do not yet know what the net is and what doors it will open. Thus-apart from the prospect of the odd Thirty Years' War ahead-I am less worried than many about the disruption the net brings. As society did with print, steam, electricity, the telegraph, and broadcast, we will figure this out. We will renegotiate our norms, abandon some institutions, and rebuild or invent others. But it will take time.

So I agree with James Dewar's prescient 1998 paper for the RAND Corporation, "The Information Age and the Printing Press: Looking Backward to See Ahead." In it, Dewar wrote: "Changes in the information age will be as dramatic as those in the Middle Ages in Europe... The future of the information age will be dominated by unintended consequences... It will be decades before we see the full effects of the information age." As a result, he argued for "(a) keeping the Internet unregulated, and (b) taking a much more experimental approach to information policy. Societies who regulated the printing press suffered and continue to suffer today in comparison with those who didn't. With the future to be dominated by unintended consequences and a long time in emerging, a more experimental approach to policy change (with special attention to unintended consequences) is soundest." I emailed Dewar recently to see whether his views had changed in the two decades since. "We still have no clear idea of what the technologies of the internet are going to be when it settles out, let alone what the societal impact will be," he responded. But he added: "The one thing that has surprised me since 1998 is the impact of the internet on systems of government." He is "worried that the internet might actually be a more powerful tool for autocracies than for democracies."

A key challenge today is that we do not yet have-cannot yet have-a definition of the net. I see it as a connection machine, connecting people with people, people with information, information with information, and machines with machines. I have no idea whether that sense of it will hold up over the decades-centuries-to come. It is too soon in its development to define, limit, and control the net. Without a proper and complete understanding of the internet and its age, we naturally fall back on analogs from the past in trying to grapple with and restrain its impact. Most often I hear media executives and the politicians they lobby call the internet a

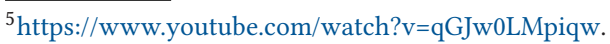

${ }^{6}$ James A. Dewar. 1998. The Information Age and the Printing Press: Looking Backward to See Ahead. RAND Corporation, Santa Monica, CA. https://www.rand.org/pubs/papers/P8014.html.
}

Digital Government: Research and Practice, Vol. 1, No. 1, Article 4. Publication date: January 2020. 
medium, and they see what appears on it as content. In the mind's eye of these media people, the net is a circle inside the larger circle of media, alongside publishing and broadcast as technologies or news, entertainment, and marketing as forms.

I say the opposite has become true: Instead, envision media as a bubble almost entirely inside a much larger circle that is the net. Today, media are on the whole a subset of the net, save for the shrinking remnants of their legacy forms: print, broadcast, and theater. Other sectors of society and the economy are, in different stages, also being drawn into the net like old galaxies sucked into an immense black hole. Communications as an industry is now almost entirely inside the net (what is a "phone" anyway?). The industry known as social was born inside. Retail, financial services, health services, education, and even crime are at earlier stages of being subsumed. And politics? Government? That is the question posed by this journal.

In the realm of politics, campaigns-good and bad-are being run increasingly online. Howard Dean campaign manager Joe Trippi presciently or wrongly titled his 2004 book The Revolution Will Not Be Televised. Thus far, he has been wrong. I hope, but I cannot be sure, that he might soon be proven right as Donald Trump becomes perhaps the last television candidate, the apotheosis of the medium and of its malign influence on the public sphere. Marshall McLuhan said that Richard Nixon lost his debate against John Kennedy because he was too hot for the cool medium of TV. As television became more high definition and-according to McLuhan's son, Eric ${ }^{7}-$ it became hotter, TV met Trump, the hottest candidate in American history. Trump burns himself out with every appearance. He destroys everything in his path: not just the medium but also the meaning of conservatism. His followers, his white base, want to return to a bygone if mythical era of nationalism and nostalgic institutions-yet they also applaud his destruction of every lasting institution of democracy: Congress, the courts, the presidency he occupies, and media. Trump and the anger he exudes and inspires destroys television itself, burning up its last remaining credibility and trust, manipulating its every moment, ruining it for every candidate to follow, none of whom can ever outdo him. Trump is heat itself. He took the cool medium and burned it up. Neil Postman was right, of course. TV amused itself to death.

And then there is Rep. @AOC, Alexandra Ocasio-Cortez, the new embodiment of McLuhanesque cool. She was not made by media because media ignored her candidacy. She won through so-called social media. I do not buy arguments that she and Trump are alike because both exploit Twitter. Trump does not use Twitter to convince; he uses it as a loudspeaker when he is not in front of a crowd with one. He shouts what mobs want to hear. He exploits Twitter to manipulate mass media, and mass media are foolish enough to go along. Ocasio-Cortez, however, uses the net to build relationships with constituents in New York and around the world (my students from India say she has become an idol there). She builds community. She keep her agenda always in sight. She responds. She learns. She drives the other side crazy. She holds a public conversation. Is she the future of politics in the net age? We can only hope.

In the realm of government, we need to wonder about the impact of this global-soon, universal-connection machine on our ideas of borders, nations, nationalities, and all else that comes with countries: armies, currencies, even laws. Said John Thornhill in Financial Times: "We remain strangely fixated on 20th-century conceptions of national sovereignty while the nature of 21 st-century digital sovereignty is being rewritten offstage in complex computer protocols." ${ }^{\prime}$ If we are passing out of the Gutenberg Age of textual society, will our norms around nations also pass into history?

We need to break free of our Gutenberg Age ideas of media, government, and society itself. The late, legendary Columbia University journalism professor James Carey would contend that we've long misconstrued the nature of society. Journalism and media are not about content; they are about conversation. So is democracy. In his essay “A Republic, If You Can Keep It," Carey argues:

\footnotetext{
${ }^{7}$ https://www.youtube.com/watch?v=Zi6jgQYhbNI\&t=619s.

${ }^{8}$ John Thornhill. 2019. The web has fallen under the influence of a bad crowd. Financial Times (March 11, 2019). Retrieved November 28,2019 from https://www.ft.com/content/333501f2-43d4-11e9-a965-23d669740bfb.
}

Digital Government: Research and Practice, Vol. 1, No. 1, Article 4. Publication date: January 2020. 
But I believe we must begin from the primacy of conversation. It implies social arrangements less hierarchical and more egalitarian than its alternatives. While people often dry up and shy away from the fierceness of argument, disputation, and debate, and while those forms of talk often bring to the surface the meanness and aggressiveness that is our second nature, conversation implies the most natural and unforced, unthreatening, and most satisfying of arrangements. ${ }^{9}$

What we are hearing on the net now, what many fear and decry and call to control, is a society relearning how to talk with itself. In almost six centuries under the sway of text and one-way, top-down, and later mass media, we lost our ability to converse. But now, with the net, we can reclaim it.

Two academics at the University of Southern Denmark, Lars Ole Sauerberg and Tom Pettitt, formulated a theory they call the Gutenberg parenthesis, in which they contend that before movable type, ideas were passed around mouth to mouth, changed along the way. ${ }^{10}$ There was little sense of ownership and authorship. The business model was simple: one scribe, one patron, one book. Scribes' efforts often were devoted to resurrecting and preserving the knowledge of the ancients. Come Gutenberg, they say, knowledge became contained in the book. Our cognition of the world became serial, with beginnings and ends-the line, and this sentence is an example, became our organizing principle, said McLuhan. A business model emerged with the Statute of Anne and copyright law, and the property metaphor for creativity was born. Rather than celebrating and preserving the ancients, textual society honored contemporary authorities and experts: Frau Dr. So-and-So, author of a book. Now, post-Gutenberg, Sauerberg and Pettitt say, our sense of ownership and authorship and the business models built around content are broken-thus the fight in the EU over Articles 15 and 17, Germany's Leistungsschutzrecht (ancillary copyright), and Spain's link tax, and in the United States over the defeated SOPA/PIPA copyright legislation. Philosopher David Weinberger says the smartest person in the room is no longer an ancient or expert but the room itself: the network that connects us. And once again, we see knowledge passed along, click by click, remade along the way. The conversation is revived, post-text. Says Carey:

Republics require conversation, often cacophonous conversation, for they should be noisy places. That conversation has to be informed, of course, and the press has a role in supplying that information. But the kind of information required can be generated only by public conversation; there is simply no substitute for it. We have virtually no idea what it is we need to know until we start talking to someone. Conversation focuses our attention, it engages us, and in the wake of conversation we have need not only of the press but also of the library. From this view of the First Amendment, the task of the press is to encourage the conversation of the culture-not to preempt it or substitute for it or supply it with information as a seer from afar. Rather, the press maintains and enhances the conversation of the culture, becomes one voice in that conversation, amplifies the conversation outward, and helps it along by bringing forward the information that the conversation itself demands. ${ }^{11}$

Ah, but the quality of public discourse sucks today, doesn't it? Is that not the commonly held judgment regarding all we read, hear, and see on Twitter, YouTube, Facebook, etc.? Trolling, terrorism, misinformation, disinformation, hate, bigotry, fear, and fraud: isn't that the catalog of ills the net has inflicted on society? That line of argument comes from media-whose monopoly on authority and advertising is challenged by the net-and by legislators and regulators, who are itching to plant their flags on this new, eighth continent.

We need much more research into the state of discourse online to understand what is really happening there, how bad or good it is, how malign or beneficial its impact is. The common presumption is that the net has us

\footnotetext{
${ }^{9}$ James Carey quoted in Eve Stryker Munson and Catherine A. Warren (Eds.). 1997. Fames Carey: A Critical Reader. University of Minnesota Press, Minneapolis, MN, 217.

${ }^{10}$ Tom Pettitt in various papers. Retrieved November 28, 2019 from https://www.academia.edu/35599461/Tom_Pettitt_Papers_and_ Publications_Gutenberg_Parenthesis.

${ }^{11}$ Carey, p. 219.
}

Digital Government: Research and Practice, Vol. 1, No. 1, Article 4. Publication date: January 2020. 
sequestered in filter bubbles of our own making, and so educators and regulators are rushing to create interventions on that basis. But a series of studies to date finds little evidence that the fear of filter bubbles is legitimate. ${ }^{12}$ Look, too, at all the interventions designed to educate young people in media literacy and news literacy based on the assumption that they cannot tell fact from fiction and that they are spreading the latter because they are spending all their time online. A 2018 study found that young people and frequent social media users are not the primary culprits sharing disinformation and conspiracy theories online; in this study, users over 65 share the vast majority of it. ${ }^{13}$ That is to say, the kids are alright; it's Grandpa who's screwing up the world. What interventions should we be designing, then, to educate Grandpa? Is the problem that Grandpa doesn't understand how to parse facts or that certain media outlets have made him angry and fearful of new voices in society?

New York Times technology columnist Farhad Manjoo recently urged journalists to all but leave Twitter, contending: "Everything about Twitter's interface encourages a mind-set antithetical to journalistic inquiry. It prizes image over substance and cheap dunks over reasoned debate, all the while severely abridging the temporal scope of the press." 14 This attitude comes from a position of extreme privilege, for Manjoo has a column in America's leading newspaper and a newsroom he can entice to cover stories that affect him.

What is so vital about the net is that communities that were long underrepresented and voices that were not heard in mass media can speak at last. But who will listen? After a terrorist in New Zealand live streamed his 2019 murder spree in Christchurch mosques, some on media demanded that Facebook kill live video. Yet without social media and live media, we would not have seen Diamond Phillips hold accountable the police officer who shot Philando Castile next to her. We would not have seen images of death in Ferguson, Missouri, sparking \#blacklivesmatter as a platform for justice. Without social media, we would not have had \#livingwhileblack to educate white America about the indignity, danger, and racism African Americans face while shopping, barbecuing, going to school, or entering their own homes as white people call police on them. Without social media, would the \#metoo movement have coalesced and finally held powerful men to account?

I fear that media are slipping into a moral panic about the net and technology, rushing to find the dangersthe bad things that could happen-without asking how bad the bad really is and without balancing that with the good that also comes with the net's new freedoms and powers. I fear that legislators and regulators are rushing downhill alongside media, eager to slay technological dragons and corporations without the benefit of evidence, research, and reliable reporting. I fear we could lose the opportunity to relearn how to hold conversations as a society before we've had the chance to really try.

Once more to James Carey:

We must turn to the task of creating a public realm in which a free people can assemble, speak their minds, and then write or tape or otherwise record the extended conversation so that others, out of

\footnotetext{
${ }^{12}$ Richard Fletcher and Rasmus Kleis Nielsen. 2017. Are people incidentally exposed to news on social media? A comparative analysis. New Media \& Society. Retrieved November 28, 2019 from https://journals.sagepub.com/doi/abs/10.1177/1461444817724170.

Frederick J. Zuiderveen Borgesius, Damian Trilling, Judith Moller, Balazs Bodo, Claes H. de Vreese, and Natali Helberger. 2016. Should we worry about filter bubbles? Internet Policy Review (March 31, 2016). Retrieved November 28, 2019 from https://policyreview.info/articles/ analysis/should-we-worry-about-filter-bubbles.

Seth Flaxman, Sharad Goel, and Justin M. Rao. 2016. Filter bubbles, echo chambers, and online news Consumption. Public Opinion Quarterly 80 (suppl 1), 298-320. https://academic.oup.com/poq/article-abstract/80/S1/298/2223402.

Elizabeth Dubois and Grant Blank. 2018. The echo chamber is overstated: The moderating effect of political interest and diverse media. Information, Communication \& Society 21, 5, 729-745. https://www.tandfonline.com/doi/abs/10.1080/1369118X.2018.1428656.

${ }^{13}$ Andrew Guess, Jonathan Nagler, and Joshua Tucker. 2019. Less than you think: Prevalence and predictors of fake news dissemination on Facebook. Science Advances 5, 1 (January 9, 2019), eaau4586. http://advances.sciencemag.org/content/5/1/eaau4586.

Axel Bruns. 2019. It's not the technology, Stupid: How the 'echo chamber' and 'filter bubble' metaphors have failed us. Paper presented at the International Association for Medial and Communication Research Conference (IAMCR'19). http://snurb.info/node/2526.

${ }^{14}$ Farhad Manjoo. 2019. Never tweet: The controversy over the Covington students shows why American journalism should disengage from Twitter. New York Times (January 23, 2019). Retrieved November 28, 2019 from https:/www.nytimes.com/2019/01/23/opinion/ covington-twitter.html.
}

Digital Government: Research and Practice, Vol. 1, No. 1, Article 4. Publication date: January 2020. 
sight, might see it. If the established press wants to aid the process, so much the better. But if, in love with profits and tied to corporate interests, the press decides to sit out public life, we shall simply have to create a space for citizens and patriots by ourselves. ${ }^{15}$

Carey wrote that in 1991, 3 years before the introduction of the commercial world wide web and 15 years before Twitter was born, there is nothing to say that journalistic and media organizations or governments or civil society could not have started a Twitter, a mechanism for the public conversation. But they did not. Technologists did. Now our mutual task is to decide how to debate the goals, design the tools, and guide the norms of a post-massmedia, conversational society. If the current institutions of media, government, civil society, and education do not play that role, others will.

Regulation is the current reflex regarding how to restrain the net and public conversation on it. With my own reflexive devotion to the First Amendment, I worry about government interference in speech. Again, I fear that moral panic rather than evidence will inform the actions governments take. Based on recent experience, I predict a rash of unintended consequences to rise out of regulation. But I understand the reflex and the need, and that is why I joined a Transatlantic High-Level Working Group on Content Moderation and Freedom of Expression organized by Susan Ness, a former commissioner of the U.S. Federal Communications Commission. At its first meeting in the United Kingdom, I was heartened to see that the discussion considered a balance of risk and benefit and embraced the need for research.

In that discussion, a different path of regulation took shape, inspired in part by recent regulatory experimentation in France. Rather than creating one-size-fits-all rules regarding bad behavior and intermediary liability on every platform, some in the working group suggested that each company be required to work with its community to establish mutual terms of service, governing not just the behavior of users-as community standards do now-but also what the companies warrant to provide. In the proposed French framework, ${ }^{16}$ users, civil society, and government regulators would have a role with companies in creating their covenants with the public. If a company fails to stand up to its covenant-whatever its assurances are-then it can be held to account by regulators. That is how the Federal Trade Commission polices consumer policies in the United States. This would require that companies provide agreed-upon data to regulators so their performance can be audited by regulators. That in turn may require governments to give companies safe harbor to provide that data as-after the Cambridge Analytica affair-I can attest that every platform is nervous about sharing any data with government or researchers, which only hampers our ability to more fully understand the impact of the net on society.

Layer atop that flexible regime of regulation a proposal for an internet court, which would decide matters of legality and relieve companies of having to determine-as, for example, Germany's NetzDG law does-what is manifestly illegal or merely harmful. Such legal judgment should never be the business of a private enterprise; that is the job of the judiciary. A platform could decide to take down content based on its terms of service-for example, following Facebook's ban on nudity. But if there is a dispute over the legality of content-for copyright violations or promoting terrorism or inciting hate in some countries-that would be a matter for a newly composed national internet court that is equipped and trained to handle a large volume of cases quickly. Given the scale of the conversation occurring on them, the platforms would still have to take on the role of policing content but would no longer also act as legislature and court. Except in the most extreme cases (see always child porn), platforms' liability would arise only after they had been notified of alleged violations in their domains and if they failed to act according to reasonable obligations. The person who proposed this idea at the working group session (held under Chatham House Rule, which is why I'm not identifying them) also said this would put the process of negotiating a nation's legal norms in the courts and in public, where it belongs. Clearly, internet courts and their decisions can be only as reasonable as the regimes of rights in their nations; Turkey, Hungary,

\footnotetext{
${ }^{15}$ Carey, p. 227.

${ }^{16}$ https://minefi.hosting.augure.com/Augure_Minefi/r/ContenuEnLigne/Download?id=AE5B7ED5-2385-4749-9CE8-E4E1B36873E4\% filename=Mission\%20Re\%CC\%81gulation\%20des\%20re\%CC\%81seaux\%20sociaux\%20-ENG.pdf (shortened link: bit.ly/2HmflGK).
} 
and others would surely use them as another means of controlling speech, but one hopes that less repressive countries could use the open process of the courts to build coherent-or at least public and thus debatable-case law around whatever limits are placed on free speech.

So let us optimistically say we can devise a regulatory scheme that slices the infant internet in a way that could satisfy the American vision of an open and commercial net and the European idea of a bourgeois and betterbehaved net. Let us also say that investment in training algorithms-and users, especially grandpas-manages to at least tame (if never eliminate) the scourges of disinformation and harassment. Let us buck the current dystopian mood to imagine such a hopeful vision for the net of the near future. Even if we accomplish those goals, to clean up the net as it is, then our task in building civil society online is far from over. We still must ask larger questions about the role components of the net can or should take in helping to shape a society based on conversation over content. What is missing? Where are the opportunities? What are the needs?

Given current conditions, the greatest need we have in this new reality is to build bridges among communities, to make strangers less strange, to rob the demagogues rising around the world of their power to demonize the Other. This concern is what led me to change my own definition of journalism: to convene communities into respectful, informed, and productive conversation. This mission for journalism-to convene communities into conversation-is one I believe can and should be shared by internet companies and technologists, as well as government itself and, of course, civil society. Carey tells us that democracy is a conversation, and so it is our mutual responsibility to serve, inform, and help improve that conversation so that it can be productive.

How? I will give you one small example. Spaceship Media, a California startup, does exactly what my new journalistic prescription requires. It finds and recruits members of communities, sometimes in conflict. In its first project, its subjects were 25 women in Alabama who voted for Trump and 25 in California who voted for Clinton. A journalist interviewed them all, establishing relationships, before they were thrown together in a private Facebook group, where it didn't take long for things to descend into our now-familiar conversational purgatory. But then something wonderful occurred: Community members came to the journalist, saying, "We're getting in trouble over here. Can you look up some things for us?" Thus, they said they wanted an informed conversation, needed facts, and trusted the journalist to provide them. Note well that in Spaceship's model, paying heed to Carey's dictum, the journalism follows the public conversation. News media came to believe their role was to set the public agenda. Spaceship turns that hubris on its head and shows how the public conversation must lead both journalism and government.

The most common "yes, but" I hear about Spaceship's experiment is that it doesn't scale. Who says that media must? The most visible change wrought by the net thus far is the death of the mass media business model and with it the idea of the mass-at last. Treating people all the same is fundamentally insulting and ultimately often racist, ignoring the identities and voices of distinct and self-defined (not demographic) communities. The melting-pot myth I grew up with presumed that we would all dissolve into one image-that of the white majority. Once we recognize and empower distinct communities, we need to respect and build bridges among them.

To imagine a media industry remade around building bridges, resolving conflict, informing conversation, and making peace, we will have to reimagine its business model. We need to rebuild that business model anyway, as it is quickly collapsing. Mass media's primary revenue stream, built on audience attention and advertising volume, collapses in an internet economy based on abundance rather than scarcity: In abundance, prices fall, desperation rises, and the inevitable result is cats and Kardashians and ultimately the clickbait candidate, Donald Trump. Remember that more than one television network boss said that Trump may be bad for America but he is good for business. Their revenue models promote conflict over resolution. Facebook is accused of doing likewise because it and the rest of the internet share mass media's advertising model. The life raft the sinking media are grabbing for-selling subscriptions-is no salvation, as there is a finite amount readers will be willing to spend when the competition is free. Paywalls also threaten to redline quality journalism for the privileged who can afford it. And besides, the subscription model is based on the idea that the net is a medium and its value lies in content rather than conversation. We will need to devise new models of support built around the value of service, community,

Digital Government: Research and Practice, Vol. 1, No. 1, Article 4. Publication date: January 2020. 
and relationships. We will need to develop a new discipline in convening, serving, and improving public conversation. That is a skill that media, government, and politics must learn-a skill schools must learn how to teach.

At my most optimistic-and I am optimistic to a fault-I believe we can reinvent and start institutions to take on the job of supporting a productive public conversation as the basis of democracy, and I believe we have the time-perhaps centuries-to figure out how to do that and how to sustain it.

But then I read two books that made me wonder and worry whether the job is bigger, whether the net could fundamentally alter our cognition of the world as movable type is alleged to have done. In How History Gets Things Wrong: The Neuroscience of Our Addiction to Stories, ${ }^{17}$ Alex Rosenberg argues that neuroscience pulls the rug out from under the theory of the mind, the idea that we can understand the motives and actions of others by enumerating beliefs and desires and how both are balanced in the brain. Rosenberg says that the skill we humans used on the savannah to mind-read our prey, competitors, and collaborators-to predict in the very immediate future which way the antelope would run and how the lion might beat us to it and how we could work together with fellow humans to win and to share the spoils-became the basis for thinking that we could also mind-read figures in history and entire nations: Why did Kaiser Wilhelm give Austria-Hungary the "blank check" that led to World War I? Theories abound because no one can know. We are addicted to and hard wired for stories that presume we can grasp others' motives and decision-making processes. But Rosenberg says neuroscience cannot find that process occurring in neurons in rats before they act-and our human neurons are not much different. In the end, he says, actions may be dictated by the experiences recorded in our neurons and winners may be decided by a process of natural selection. Thus, as Newton's laws robbed the universe of purpose set by gods and as Darwin's discovery of evolution robbed biology of its grand and conscious purpose, Rosenberg's neuroscientists essentially disabuse humanity of the belief in purpose, making us players in a giant tournament of game theory.

Now add the perspective of David Weinberger in his latest book, Everyday Chaos: Technology, Complexity, and How We're Thriving in a New World of Possibility. ${ }^{18}$ He begins by demonstrating how machine learning and A/B testing can analyze data to predict actions for which there may be no explanation we can understand:

Deep learning's algorithms work because they capture better than any human can the complexity, fluidity, and even beauty of a universe in which everything affects everything else, all at once. As we will see, machine learning is just one of many tools and strategies that have been increasingly bringing us face to face with the incomprehensible intricacy of our everyday world. But this benefit comes at a price: we need to give up our insistence on always understanding our world and how things happen it.

Oh, no. We came to believe that we could understand our world, the actions of individuals and of society as a whole, and we built institutions-journalism, law, courts, education, literature-around that assumption. What if we cannot explain the world that data tell us we live in? How unsettling will that be? What then becomes the basis of our public conversation if not beliefs and desires-the theory of mind? As unsettling as it might be to lose our grip on the certainty of explanation, society could welcome machine learning's ability to more reliably predict behaviors, if that brings substantial economic or safety benefits (see the arguments that autonomous vehicles will drive more safely than we do or that artificial intelligence will help diagnose disease better than our doctors). Imagine, too, that bias and impact in machine learning's data and formulae can be tested and regulated. Today, I see a rising moral panic not just about technology and technology companies but also about data itselfabout knowledge, then. But the public will increasingly depend upon data that can inform both our conversations and our algorithms.

\footnotetext{
${ }^{17}$ Alex Rosenberg. 2018. How History Gets Things Wrong: The Neuroscience of Our Addiction to Stories. MIT Press, Cambridge, MA.

${ }^{18}$ David Weinberger. 2019. Everyday Chaos: Technology, Complexity, and How We're Thriving in a New World of Possibility. Harvard Business Review Press. Boston, MA. (Read in galleys).
}

Digital Government: Research and Practice, Vol. 1, No. 1, Article 4. Publication date: January 2020. 
No matter what form the public conversation takes-citizen to citizen, data to citizen, data to data-our task today in government, civil society, and media is to build a better scaffolding for that conversation. I believe that begins by building new services that prioritize and reward listening over speaking, curiosity over contention, a safe space where people can tell their stories, where strangers can ask respectful questions, where understanding-not necessarily agreement-is an anticipated outcome. We in media need to consult other disciplines-anthropology, sociology, neuroscience, psychology, philosophy, education, data science, design-to reconsider our value, our impact, and our role as teachers, bridge builders, even therapists. We need to rebuild the business models of both media and technology-and thus advertising-around value over volume, relationships over attention. We need to formulate different metrics to account for our impact and value, means to measure the quality of the public conversation (how informed is it? how respectful? how curious? how open?). Finally, we need to build institutions-government, technology, media, education-upon principles that include openness, accountability, service, collaboration, constructiveness, and mostly respect: respect for the good will, intelligence, rights, and agency of the people we serve, who are building their future society with new tools in a new reality. That work has barely begun.

Received April 2019; accepted July 2019

Digital Government: Research and Practice, Vol. 1, No. 1, Article 4. Publication date: January 2020. 